\title{
Contextualizing music to enhance music therapy
}

Contextualizando a música para melhorar a musicoterapia

Contextualizando la música para mejorar la musicoterapia

\section{Bernard Guerin ${ }^{1}$}

[1] University of South Australia I Título abreviado: Contextualizing music to enhance music therapy I Endereço para correspondência: School of Psychology (Magill Campus), University of South Australia, GPO Box 2471, Adelaide 5001, Australia I Email: bernard.guerin@unisa.edu.au I doi: 10.18761/PAC.2019.v10.n2.03 
Resumo: Ainda que inegavelmente eficazes em ajudar clientes, musicoterapias se baseiam em tautologias e abstrações para explicarem o que acontece e isso limita sua abrangência. $\mathrm{O}$ presente artigo se fundamenta em uma forte posição contextual que dá ênfase aos efeitos observáveis de "musicar" nos contextos de vida das pessoas, especialmente os contextos sociais, e também destaca como eventos "internos e privados" emergem do mundo social. Os vários tipos de comportamentos, contextos e efeitos musicais foram revisados. Foi feita uma comparação com uso de linguagem, demonstrando que música não é uma verdadeira língua mas que isso traz vantagens para as musicoterapias. Os efeitos principais do "musicar" são, grosso modo, agrupados em três categorias: efeitos emocionais nos ouvintes; efeitos atencionais ou distrações; e discursos sobre música ou intepretações. Assim como na linguagem, o "poder" da música para exercer tais efeitos depende de relações sociais e não da música (ou linguagem) em si mesma, e, portanto, pode ajudar a redefinir ou reinterpretar as trocas nas relações sociais das pessoas enquanto tocam ou ouvem música. Música pode distrair eficientemente do uso excessivo da linguagem em nossa sociedade e acalmar por suplantar pensamentos ruins ou conflituosos baseados em linguagem. Foram feitas sugestões ao longo do texto sobre como terapias podem aprender com análise contextual, com comparações com usos da linguagem, e com técnicas das terapias cognitivo-comportamentais, terapias narrativas e hipnose.

Resumen: Aunque innegablemente eficaces en ayudar a los clientes, las musicoterapias dependen de tautologías y abstracciones para explicar lo que sucede y esto limita su alcance. El presente trabajo se fundamenta en una fuerte posición contextual que pone énfasis en los efectos observables de "musicar" en contextos de vida de las personas, especialmente los contextos sociales, y también destaca como eventos "internos y privados" surgen del mundo social. Se han revisado varios tipos de comportamientos, contextos y efectos musicales. Se hizo una comparación con el uso del lenguaje, demostrando que la música no es una verdadera lengua, sino que esto trae ventajas para las musicoterapias. Los efectos principales del "musicar" son, grosso modo, agrupados en tres categorías: efectos emocionales en los oyentes; efectos atencionales o distracciones; y discursos sobre la música o interpretaciones. Así como en el lenguaje, el "poder" de la música para ejercer tales efectos depende de relaciones sociales y no de la música (o lenguaje) en sí misma, y por lo tanto puede ayudar a redefinir o reinterpretar los intercambios en las relaciones sociales de las personas mientras tocan o escuchan música. La música puede distraer eficientemente del uso excesivo del lenguaje en nuestra sociedad y calmar por suplantar pensamientos malos o conflictivos basados en el lenguaje. Se hicieron sugerencias a lo largo del texto sobre cómo terapias pueden aprender con análisis contextual, con comparaciones con usos del lenguaje, y con técnicas de las terapias cognitivoconductuales, terapias narrativas e hipnosis. 
... a musical system should first be analysed not in comparison with other musics, but rather in relation to other social and symbolic systems within the same society. (Blacking, 1995, p. 228)

Writing about music is difficult because a large part of what has already been written is made up of tautologies, metaphors, and abstractions. Because no clearly seen object of music itself appears (just invisible sound waves), this makes it seem difficult to observe a material basis for music making and so it is easier to take abstract or tautological 'explanations' seriously, and place agentive events in the head or brain. The answer, as I will outline, lies in viewing music as a verb or activity (Small, 1998), and then replacing any theories or abstractions with careful descriptions of the social contexts or ecologies (DeNora, 2011) in which music activities occur, and the effects which arise from these (Guerin, 2001a).

The aim of this paper is to contextualize music in this way to suggest how and why music therapy can help people in various ways, but to do this the paper will need to first focus on analyzing what music does to people and what people do to each other with music. Music will be compared to language use but with the differences stressed because this will become important when later examining the differences between language-based therapies (psychotherapies, clinical psychology, hypnosis, counselling) and musical therapies. Most of the practices of music therapy are useful and effective (e g., Landis-Shack, Heinz \& Bonn-Miller, 2017; Vink \& Hanser, 2018) but the explanations also follow the common and philosophical ways of using abstract theories. My aim is to find new ways forward by opening up some of these abstractions and mentalisms for more detailed scrutiny.

\section{What is music and what can we do with it?}

To contextualize music, we must look at the behaviors involved (and this includes all of acting, talking and thinking), the contexts in which they occur, and the effects (Guerin, 2016a). In general, this will encompass (1) the learned manipulation of sounds in context and (2) what that does to people (since the effects only occur for people). It will become important, however, that the effects of any 'musicking' (Small, 1998) are not necessarily due to those manipulated sounds per se but might also arise purely from the (social) contexts of their occurrences. What this means is that to analyze the material basis of musicking we must look for the ways in which sounds are manipulated and how people have learned to respond in musicking contexts, whether or not this is due to the music sounds themselves. As for language (Saussure, 1983), the manipulated sounds might in themselves be arbitrary and not important.

In this way, it is more useful to think about the role of music or manipulated sounds as like the role of kangaroos for the traditional aboriginal groups living in the Australian deserts: kangaroos already existed with their own ecology and functioning but the humans could engage with them in multiple ways. Kangaroos provided many different types of meat, skins for clothes, skin and sinews for useful tools, bones for several purposes, and even as pets. But they also served as totem animals in the conceptual schemes of the social groups, and as markers of respect when dividing the meat in communities. In this way, the groups did whatever they could usefully do with kangaroos and it is pointless to try and find the one 'main' function of hunting kangaroos, what kangaroos really 'meant' to these people, or trace back all uses to kangaroo meat as 'reinforcers. As the opening quote from John Blacking indicates, we must examine kangaroo hunting from all that group's systems rather than compare to how other groups have used kangaroos.

Similarly, many objects in our worlds make sounds when we hit them, rub them, blow on or through them, or scrape them with another object. These are their ecological properties (Gibson, 1979) but there is not one 'main' thing that humans can do with those sounds if they are produced, and the sounds themselves do not 'mean' anything (sounds are not sad or happy in themselves). New 'uses' for music and new sound manipulations have always been happening and are still being created today (Chanan, 1995; Duffin, 2007; Rosen, 1980). An example from some decades ago would be 'elevator music', and a newer example would be scratching or scrubbing of LPs on a turntable. 
Apart from the special case of sudden noises or loud sounds which get immediate attentional effects, and which occurs for most mammals and birds, making sounds probably only has its most useful functions when other humans are involved together and the music itself might be of less importance-more like the different social uses of kangaroos as totems or markers of respect than like their uses as food. We cannot eat music to survive but we can utilize music to regulate cooperative groups and social relationships to survive, as we do for language use.

The function of getting or changing attention develops beyond only sudden, loud noises, however, when utilized in social ways but like all social uses this requires some learning in a social context. A sudden switch from a slow $A m$ piano segment to a slow $E$ flat segment will get attention in this way only for those with suitable training in western music, whereas the shift between the $1^{\text {st }}$ and $2^{\text {nd }}$ Movements of Shostakovich's $8^{\text {th }}$ String Quartet could do both, and may even startle other mammals if played loudly. In this regard, music is similar to language and even shares with language the manipulation of sounds (but produced by the mouth in the case of language uses).

Overall, then, our starting point for contextual analysis is that humans work from what the environment affords (Gibson, 1979) in the way of manipulating sounds, but that our complex social environments allow other functions and effects (meanings) for both music and language. We need to closely examine and describe the behaviors occurring for musicking, the effects, and the contexts in which they do and do not have these effects. Before that, however, as John Blacking recommended, I will discuss some of the features of another human system of doing things to people with sounds and markings-language.

\section{What is language, what do we do with it, and how does this compare to music?}

Language has often been compared to music but using many metaphors, abstractions and tautologies (Austerlitz, 1983; Aiello, 1994; Barthes, 1985;
Feld \& Fox, 1994; Kassler, 1991; Natteiz, 1990). The four main abstractions and tautologies used to 'explain' language functioning are also used for music-express, communicate, refer to, represent (Guerin, 2020a). I will focus here on the differences between music and language use mainly because these are less often mentioned and because these will be used to compare language-based therapies to music therapies later.

Language takes up a large amount of childhood, devoted to learning systematically how to wield words and discourses to do things to people (Guerin, 2003, 2016a). Music is different in this way in that many fewer people learn to perform or create music, but most people have probably spent a lot of time listening to musics and talking about musics but in a far more unstructured way than for language (I will come back to this point). Clearly less time is needed and is given for learning to listen to music than to perform music and, in this way, it is different to language use.

Language use is so complex and nuanced, in fact, that to work at all it depends upon a very careful ordering of sounds to achieve smooth and rapid functionality, and hence needs well-trained grammars of different sorts to achieve this. While some composers and players spend a lot of time learning how to write and play sequences of carefully specified music (especially in western musics rather than folk musics), the exact sequences are not standard or normalized in any way like the grammatical sequencing of language use. One can manipulate the English sequence of sounds, "p-lee-s go to the caaa", and with the right social relationship (I will come back to this), the listener will go to the car. There is nothing like this in music but at least we do not need to spend as much time learning music, and we do not need to learn a 'correct' grammar of musical sounds. A reviewer correctly pointed out that two musicians can do things to each other, but only in regards to playing the music-one cannot get the other to go and make popcorn with music.

Each genre of music, of course, encourages certain recognizable patterns of sound (e. g., for metal versus string quartet) but this is not like a language grammar. A real musical grammar would consist of spending a long time learning set sequences which could then be recombined, such as: singing a, a, c\#, 
$c \#, d, c \#, b, g$ and a trained listener would go to the car; playing a, a, c\#, c\#, d, g, a, g and the listener would go to sleep; or playing d', e', c', c, g' for someone to make contact. An upper mordent on the first note in a sequence might be past tense and a lower mordent might be future tense.

This is an important point since if you understand what is being said, it really demonstrates that the functioning of music and language are very different, and that people performing these two sound activities are doing very different things to listeners. In this way, music is not like a language and the vague word 'communicates' is usually used to blur the distinction when it is said that both music and language 'communicate'. If we jettison the word 'communicate', which really only means 'has learned effects on people', we can see that music and language are doing markedly different things to people.

A common feature of both language and music is that we can 'hear' both even when no speaker or performer is present, and we call these events thinking. Our 'thoughts' in the sense of language use are not uniquely inside of us as (every behavior also involves our bodies) but 'in' our social relationships and the large number of conversations and discourses we have (Guerin, 2016a, 2017a, 2020a). Thoughts do not 'pop into our heads' as we say, but 'pop into our worlds', 'pop into our contexts', or 'appear in our discursive environments. They are snippets of discourses and conversations that we might have said previously, might have heard someone say previously, might be able to say another time, or are the things we never got to say. As Freud and others noted, they are most frequently about the bad, conflictual or unresolved situations in our lives, but not always. You can 'rethink' a funny thing a friend said the day before, and even smile as you do. But it is a mistake to assume that 'we' decide when and what to think, since this is determined by our contexts or life situations.

In a similar way, most people I know, to different degrees, can 'hear' music when none is begin played. Composers can hear a whole new work without writing it down or hearing it played out loud in many cases. This is mostly taken as a 'normal' event and not, like language, as a case of pathological 'hearing voices'. But like 'hearing voices' (Guerin, 2017a, 2020b), hearing music is not actually a problem issue until it starts to interfere with everyday life functioning, such as when relentless repetition or the repeating of disliked music becomes a problem (e. g., an earworm from "The Sound of Music"). Once again, this is not determined by some inner, agentive person since such events just 'pop into our worlds'. They are controlled by our contexts and 'you' do not get a choice of when 'as if spoken' thoughts or 'as if played' music will happen. You can control these to some extent, however, but by controlling the conversational and discursive events in your life (as cognitive behavior therapies do), and by controlling the external sounds in your life. I will come back to this when looking at musical therapies.

If we next look at the functions of language, there are various ways these have been categorized. I employ a flexible scheme since people constantly do new and inventive things to other people with language (Guerin, 2016a). In this scheme, language has two main functions: getting people to do things and forming and maintaining social relationships. There are many ways to do these which depend heavily on the contexts, and this is why more fixed category schemes fail.

A complex language example of 'getting people to do things' might be, "Could you please remind me tonight that we have to get all the Xmas baubles into a box and then put them in the car ready for the party tomorrow night?" If you think in terms of training an animal to do this, or getting someone to do this only by playing a flute to them, this piece of functional language is extremely complex, quick, very specific, and really quite amazing. However, it does depend on many years of training and practice, and having a listener who has been likewise trained in the same language and dialect ("Coods ye please remin' me tonecht 'at we hae tae gie aw th' xmas baubles intae a box an' 'en pit them in th' motur ready fur th' ceilidh tha' moorns nicht nicht?", courtesy Whoohoo.co.uk).

Examples of the second broad language function, "forming and maintaining social relationships", include jokes and humor, rumor and gossip telling, the use of politeness and adjacency pairs, complaining talk, story-telling, compliments, conflict meditation, discursive repairs, hedging, and 
much more (Guerin, 2016a). In these examples, which have led philosophers astray, the function is to engage with the other person and maintain a social relationship rather than say anything that is necessarily true or which gets them to do something specific. The language use is functioning and working well if it supports the relationship even if wildly inaccurate things are being said. These uses of language are maintained by the many outcomes or effects of having functional relationships.

I will summarize more about the specific functions of music below, but if we compare music to language it should be clear already that music can do almost nothing specific with respect to 'getting people to do things' given the lack of training to link standard phrasings and note patterns to people's specific behaviors ("please go to the car"), and the lack of a grammar to make this functioning fast and smooth. Music does, however, function with respect to 'forming and maintaining social relationships' given that 'musical meaning' is really about forming and maintaining social relationships as effects of musicking and not about expressing, communicating, referring to or representing anything more than this. Rather than music telling or instructing people about what to do, music seems intuitively to be more about an activity which helps form and maintain social relationships, but, like our kangaroos, not in a single or unique way. In this sense, a composer does not express, communicate, refer to or represent anything; instead they do things to people but not with the same sorts of outcomes as language. Musicking in all forms is about doing things to our relationships.

There is a big exception to what has just been said, which I will outline below. I will argue that despite the huge impact and benefits of language use to humans, there are at least two serious gaps in what we can do to people just by using language, and that these figure largely as problems in 'mental health' (Guerin, 2017a, 2020b). These two language gaps are (1) that there are things and events which language cannot easily refer to and get ignored, and (2) that the 'power' to get people to do things with language is not part of the language itself but depends upon the social relationships with listeners in any case. We will see that music can usually fill in these two gaps to some degree, along with dance, poetry, theatre and mime, other non-linguistic actions, and painting and drawing. The argument will be that these gaps in what language can do are important in music therapies.

\section{What are the musical behaviors, their contexts, and their effects?}

Outlining all the behaviors and effects of musicin-context is obviously too large for one paper so I will give some main points. Large clusters focus around behaviors of (1) composing, (2) performing the manipulation of sounds, (3) performing the organizing of musical events, and (4) listening or otherwise participating during musical events. In terms of what is done and what are the effects on people for 1 to 4, we must remember John Cage from 1966 (Nyman, 2006, p. 210): “Composing's one thing, performing's another, listening's a third. What can they have to do with one another?" It is also important to note that music therapies have mainly focused on utilizing 2 and 4, but occasionally 3 in some important cases of using community events as musical or community 'therapy' (Ansdell, 2014; Clunies Ross \& Wild, 1984; DeNora, 2013; Moyle, 1986).

\section{Behaviors}

The activities involved in musicking are mostly well-known although listening is usually treated as a private, passive reception rather than an activity, but this is only because what is done in this activity is not easily observed (Guerin, 2020a). Unlike the metaphors which have been used to fill this gap, the position here is that the behaviors of listening are difficult to observe not because they are private or hidden inside a person's brain or 'soul', but because they are attentional and discursive social activities which, although difficult to observe, are in the world and our actual social exchanges and not originating in the head (Guerin, 1990, 2016b). So, listening is not passive reception, but it is not active in the sense of something internal or inside us being motivated or agentive and 'wanting' to hear things. It is active in the sense that our social contexts and histories channel us into patterns of attention and talking (thinking). 
The main activities for music are: manipulating sounds such as playing an instrument or singing; listening to someone play; hearing music without it being performed (what we call metaphorically, 'in your head'); attending to and discriminating sounds in relation to events in your world; behaving in socially learned and appropriate ways to music; organizing groups to perform musical events of many sorts; learning how to talk about the music with respect to different social relationships, histories and contexts; learning how to incorporate music into talk about other social relationships, histories and contexts; and learning other ways to incorporate music into life social strategies. These are the basic materials for music therapies.

\section{Contexts}

The main contexts for musicking of all sorts are social, meaning that musicking is done in contexts of groups and social relationships and that the effects from those social relationships and societal contexts is what makes music functional. This is widely recognized in the literatures on music (e. g., Blacking, 1995; DeNora, 2011; Feld, 1984; Merriam, 1964), except that the social contexts from which musical thinking and listening arise are often not then observed and described, because they have been assumed metaphorically to be private or 'inside the head'.

There are many schemes put forward for delineating context, with some purely conceptual and some more aimed at observation and documenting (e. g., Seeger, 1987, pp. 128ff) and I will illustrate with a few. For example, Seeger (1962) presented contexts for music with seven extrinsic and nine 'intrinsic'. In the present approach, most of the 'intrinsic' are parts of the (hidden) social contexts or the historical contexts (of a person), so the events are really extrinsic anyway. Despite that, the categories might be useful for intensive studies to document the contexts for musicking. He lists as extrinsic: geographic area; culture area; political area; social strata (opportunities); sex, age-group, occupation; social functions; foci of interest. 'Intrinsic' are: own and not-own traditions; own and not-own tastes; expert and less expert; creative and re-creative; written and unwritten; self-made and made by others; free and priced; traditional and non-traditional; music-technical functions.
Kingsbury (1998) proposed six main categories of the social relationship contexts for music, that he found to be important in his study of a conservatory: composer, performers, public audience, scholarly musicologists, journalistic critics, and private teacher-student dyads. "Such a sixfold configuration, taken as a mode of cultural production, a configuration of collective action, is suggested as a preliminary conceptualization of the present study" (p. 18).

Feld's (1984) proposed a detailed scheme of questions to ask, based around competence, form, performance, environment, theory, and value and equality. Clearly the 'environment' needs further delimitation, but all are worth pursuing. In a different area, I work broadly with social relationship contexts, economic contexts, cultural contexts, opportunity contexts, and historical contexts to make sense of what humans do (Guerin, 2016a). In these terms, probably least attention is given to the economic and opportunity contexts of music.

\section{Effects}

Many readers will note with puzzlement below that I am not including any effects of music on the brain or brain functioning. Without going into all the arguments, this is because I see the brain as involved (along with the whole body) in all of the effects below but that the contexts and history originate these effects, they do not originate from, nor are created by, the brain itself. Given that almost all the related neurological findings are correlational, I find it more useful to see the 'brain effects' (e. g., Bicknell, 2009) as correlational with the effects of external contexts and previous effects, and not causal or agentive. One also finds this more palatable after examining the discourse analysis literature on the strategic uses of 'mentalisms', which are both hidden from scrutiny and abstract, and used in discourses for suppressing challenges to what is being claimed (Guerin, 2016a). The discursive uses of the 'brain' are a way of hedging what we do not know (Guerin, 2020a).

The questions to ask for musical effects or functioning are: what does music do to people and what can we do to people with music? What can the music itself shape and what can people shape others to do by utilizing musical events? This includes at least 
four questions based on what was said earlier: what can we do to people using composing, performing the manipulation of sounds, organizing of musical events, and listening or otherwise participating in musical events?

As already mentioned, the main effects of all sorts of musicking arise from what this does for social relationships, and this even includes the effects of listening to music on social relationships (although it is treated usually as a closed private system). Most of this has been hidden in theories, metaphors and abstractions. A good example is Merriam's (1964) ten functions of music: emotional expression; aesthetic enjoyment; entertainment; communication; symbolic representation; physical response; enforcing conformity with social norms; validation of social institutions and religious rituals; contribution to the continuity of the culture; contribution to the integration of society. What Merriam is getting at is not disputed, only that these abstract words do not allow easy observations, and that they cover up difficult to see social relationship effects (such as the first five).

To give one of many examples, Merriam's aesthetic enjoyment, entertainment and symbolic representation might all be effects of the music on your future social conversations. Listening to music (even while seeming to be passive) allows stories and discourses for your social relationship audiences, such as: who you are or self-identity talk; what you 'felt' at the concert; how that reflects on you and your integrity; funny stories about incidents; inducing jealousy; or intellectualizing what you heard. These do not always occur, they are just to demonstrate that 'passively' listening to music is a rich vein for future discourses you might have and this is only one social effect of music. If you watch a person listening to music you do not 'see' these since they are interactions at another time and place. But if you intensively study that person over time, as an anthropologist or many ethnomusicologists would, you will observe these effects of music in that person's 'extrinsic' social world (Guerin, Leugi \& Thain, 2018).

Elliott Carter (1977, p. 28) gives a good example of these different effects on our social relationships while listening to music, of how our social relationships change while listening to music (even though like everyone else, he has located them 'in the head'):

There are two ways of listening to music. The most popular is for the listener to give himself [sic] up to an evening of reminiscence or reverie after having checked his conscious, critical self at the door with his hat. The small spot he has in his heart for music awakens and he evokes personal images and feelings which only remotely correspond with what is striking his ear. Scenes from childhood and adolescence are evoked by the Debussy or Chopin number, heroic justification of acts he could not make up his mind about is found to the tunes of Brahms, Beethoven, Sibelius, or Wagner. If he has any room for modern music he thinks over the sad situation of his bank balance or love life to the agitations of Strauss or the hysterical post-war Germans, and finds anxiety for his own future aroused by the proletarian theatre composers. Though by constant repetition he may discover something to hook on to the most diverse styles and thus find a way of not paying attention to them, he generally rejects any music which jars him out of himself and threatens to afford a new experience, giving way to anger as a protection.

There is a more objective though just as enthusiastic kind of listener. He is eager for new ideas and new feelings. When hearing familiar works he always re-evaluates his previous impressions. The style, no matter how difficult or unusual, does not prevent him from trying to find what the music is all about. He follows it attentively for he knows that it is a living message to him from another living man, a serious thought or experience worth considering, one that will help him to understand the people about him. To him, dead, worn-out formulas or non-communicative styles are anathema. Serious composers and musicians have always aimed at this listener and he in turn has shown that he could take his listener's share of responsibility by keeping his mind actively fixed on the music he was hearing.

We must keep in mind with what is written above that Carter has the listener doing all these things to themselves, whereas the position of this 
paper is that they are bits of conversation and other discourses for use later in the listener's social relationships which can be reshaped by these effects of music. One important point we will come back to is that of "after having checked his conscious, critical self at the door with his hat". This is common for music, music therapy, psychotherapy, and hypnosis, and is an important therapeutic effect I will return to below.

So, the 'meanings' of music are really its effects or consequences, and they are primarily social in that by hearing music, our relationships with friends, family and even strangers can be changed in multiple ways (Guerin, 2016a). This is why we cannot observe these effects directly while music is happening and resort to placing them in private places in the head or soul.

The effects of music are therefore real but need to be observed in social relationships over time using different research methods, as examples illustrate. Kaemmer (1989) puts this well in relation to the Shona people in Africa: "A second generalization concerning stratified societies is that the natural environment may be less influential in determining musical activity than is the social environment. In the case of the Shona, the mode of production [of music] was imposed by the social system rather than developing out of the exigencies of the environment." (p. 45)

As Shepherd (1992) also writes: "A central problem in understanding significance in music has been that, in their most 'abstract' manifestations, the sounds of music do not obviously refer outside themselves to the world of objects, events and linguistically encodable ideas. In terms of the way in which symbols are commonly understood to have meaning music emerges either as having 'no meaning', or as having a meaning that is quite distinct and apart from all other forms of meaning." (p. 130-131). That is, music does not 'refer to' anything but affects the hidden social relationships directly so that before and during music aspects of the persons' social relationships have changed, even in the stories they can tell.

Blacking (1969, p. 59) says a similar thing: "I have presented evidence to support my argument that the function of music is to enhance in some way the quality of individual experience and of human relationships, that music is a metaphorical expression of feeling which can communicate with 'a detail and truth that language cannot approach,' that its methods of communication vary according to its role in social life, and that its structures are reflections of patterns of human relations in culture."

The only change is that in the contextual approach of this paper, the "quality of individual experience and of human relationships" are the same. The same applies to other statements about the effects of music being social: "Music systems are but one way in which the people of a given culture conceptualize and make sense of their world." (Becker, 1979, p. 197). Like meaning, however, we do not need to 'make sense' of our worlds; that is a common metaphor for the hidden effects of social events, in this case, of music changing our social relationships (Guerin, 2001a, b).

So far, I have discussed briefly some of the general effects of music with examples, and have emphasized that most are effects on current or future social relationships which are real but we cannot see them without intensive observations over time. But there is a lot of good literature on more specific effects of music, as put sarcastically (and perhaps arrogantly) by Igor Stravinsky: "What disturbs me about Wozzeck, a work I love, is the level of its appeal to 'ignorant' audiences, with whom one may attribute its success to: 1) the story; 2) Bible, child sentiment; 3) sex; 4) brevity; 5) dynamics, pppp to ffff; 6) muted brass, col legno, etc.; 7) the idea that the vocal line=emotion; 8) the orchestral flagellation in the interludes; 9) the audience's feeling that it is being frightfully modern." (1963, p. 23)

The other main musical effects fall roughly into three categories: emotional effects on the listeners; attentional effects or distractions; and discourses about music or interpretation. These are similar to those of Bicknell (2009, p. 47): crying and chills (with no words); absorption; and cognitive meaning or interpretation (about words).

Bicknell (2009) gives a good summary of the 'emotional' effects of music, as it has moved in history from helping 'afflictions of the soul' to relief, and the ability of music to produce tears, trembling and collapse. The emotions produced can incite people to battle, induce joy, inspire courage, produce a feeling of the sublime, or produce longing. The atten- 
tional effects can 'take one out of oneself', and produce trance states and overwhelming feeling of awe which distract (Rouget, 1985). The cognitive meaning effects are really about how one's conversations and discourses can be changed by listening to music although, as outlined above, this is about changing our social relationships not some 'inner self' monologue.

This brings us to an interesting example of mixing attentional and 'cognitive' (i. e., language use) effects. Bicknell (2009) writes about the effects of music on 'inner speech', but with a mix of attentional and 'cognitive' effects: "When we listen to music and let it dominate our minds, inner speech ceases and is replaced by music." (p. 114). But once again, we as an agent do not let it dominate, our contextual situations shape this, and this will be important in the discussion below.

This has also been the basis for statements that an effect of music is to overwhelm reason or subvert people's reason. Common in both Christianity and Islam, this is also true in the last few decades when societal groups (the 'moral majority') argue that all sorts of young people's music are bad for them by inducing dangerous emotions and leading them to do unreasonable and immoral things (Rowe, 2018; Rowe \& Guerin, 2018; Weinstein, 2000; Winegarner, 2013). But elsewhere I have argued that the opposite of rational is not 'irrational' but social (Guerin, 2017a, pp. 159-162). That is, we are considered irrational when we are shaped by social relationships rather than by logic, but in many cases, this is actually a reasonable (or rational, in fact) thing to do. This again highlights that the 'forces' as it were of music are about social relationships and this now includes emotion itself but only in certain contexts to be outlined below.

To conclude, we have seen that musical effects can be put into three categories: emotional effects on the listeners; attentional effects or distractions; and discourses about music or interpretation. However, each of these is about effects that occur, or will occur, with the listener's normal audience relationships-our attentional effects are guided socially, our discourses and associated 'thinking' are shaped by our audiences in everyday life, and emotional responses are brought about socially and have something to do with the lack of language or distraction from language thinking.
So, to frame this another way, from all the effects of listening to music, what do we gain directly and what do we gain by avoiding something aversive? Examples of positive gains from listening to music we have seen are that it gives us something to talk about socially, gives us some self-identity talk for use in everyday life so we can appear cool or hip or whatever is current, and can be used to build and manage social relationships. Music also helps us to avoid any anxiety and be calm, and this probably happens by music's effect of distracting us from negative thoughts and relationship conflicts. It can also distract us from the main directive and critical voices we might have or as a way of controlling many (the nagging language voices).

\section{Where does the Power of Language Use and Music come from?}

Before continuing to look at therapies and music therapies, there are three closely related questions that are important to cover. The first is the question of how music, manipulating sounds in the environment, can bring about any effects whatsoever - where does the power of music (and language) come from? The second question is, what happens when we cannot explain or talk about someone or some event; what do humans do when language fails us? The third question is the nature of what has been commonly called 'emotion' in musicking, and the answers to this will come from what we learn about the first two questions.

\section{The power of music and language}

Probably the biggest problem for understanding music and the one which produces the most uses of metaphors, tautologies and abstractions, is the question of how music (and language) can get us to do anything anyway? How does banging, blowing wind, and scraping horsehair over strings, get so much of our time and money? How do we get powerful experiences from music (Gabreilsson \& Lindström Wik, 2003; Lamont, 2012)?

Clearly the 'power' of music does not come from the music itself: "I consider that music is, by its very nature, powerless to express anything at all, 
whether a feeling, an attitude of mind, a psychological mood, a phenomenon of nature, etc.... If, as is nearly always the case, music appears to express something, this is only an illusion, and not a reality." (Stravinsky, quoted in Cooke, 1959, p.11). Or as Ansdell put it better: "We suggest that music doesn't have some magical power in itself, but rather that what music can uniquely do shows up between people, within situations, and about specific local needs and possibilities. Music comes to life and quickens others only within and amongst a musical ecology." (Ansdell, 2014, p. xvi)

So, what gives music the power that it obviously has (Blackwell, 2005)? Music certainly appears to have a huge power. We spend a big part of our time on music, communities base a lot of their joint time around music, most of us spend a lot of our money on listening to music whether live or recorded, and musicians are notorious in all genres and parts of the world for spending more money to make their music than they ever receive back.

To answer this question, we will look at the power of language from a contextual view. There are other ways this might be analyzed, and readers are encouraged to pursue these. For example, there are demonstrations of 'mood' being 'transferred' through equivalence relations (BarnesHomes, Barnes-Homes, Smeets \& Luciano, 2004; Cahill, Barnes-Homes, Barnes-Homes, RodriguezValverdes, Luciano \& Smeets, 2007). For this paper, however, the whole idea of any music being 'sad' or 'happy' in itself is begging for further social analysis and many musicologists disagree with this way of talking. It is not clear what is even meant by 'mood' or 'emotion' and this needs further analysis (Guerin, 2020, Chapter 6). But this should be pursued further elsewhere to get a strong social analysis of the contexts for what is currently labelled 'mood', and therefore what functions are actually being transferred (it could be other sorts of social functions being transferred).

But for the current paper, language works, does things or has effects or consequences by the reciprocal relationships with the listener, and this means what we can do to people with language. The power of language is not what happens when you speak but what your words do to the listeners or eventual listeners and what they do for your strategic social world (Guerin, 2020). Language allows us to have quick and smooth social exchanges that provide us everything we need (through forms of social reciprocation).

You cannot just command someone because of the words you use. Your words only 'work' if the social relationship is functional, through reciprocities which are different for different forms of relationships. Words work with strangers only if we have an appropriately reciprocal relationship in place already, and for strangers this means money in most cases (Guerin, 2016a). If I just ask a stranger to mow my lawn they will not do it, but if I pay them, and if that is useful for them as well as for me (and if I have the money), then my words suddenly and miraculously have 'power'! Words work with the power of social relationships, even though you cannot see this without long and complex observations over time. Most of the time we just observe the words being spoken and see the listener do appropriate behaviors. We do not see the social reciprocity because it happens somewhere else or at another time.

With family and friends, as an example of a different social reciprocity, we can ask some of them (the ones with appropriate relationship and history) to mow our lawns and they will just do it without being paid. But this is because the form of reciprocity here is different: it is usually the long-term reciprocation of favors of different sorts which are again difficult to observe unless you use intensive research methods (Guerin, Leugi \& Thain, 2018). Using quick observations and only in the place in which that language was used will not show you what is actually going on. Once again, it will seem that the language use miraculously works and that language must have a secret power inside of the words somehow.

So, the power of words to get people to do things does not come from the words themselves, and they can be thought of as a surrogate way of getting people to do things other than by direct physical means. This surrogate way is very quick and can achieve extremely complex behaviors in the listeners, but only if the social relationship reciprocities and other conditions are in place, and only because of the time we spent in our early life learning the complexities of language use, something mentioned earlier. 
If you can get the idea that language only works because of the resource interdependencies in our social relationships, then you can begin to see the same for the 'social power' of music to 'move' people (Bicknell, 2009), even when they are alone (Guerin, 2001b). But as I have stressed, the social properties and the effects of music are not quite the same as for language, so what we can do to people with music, how that gets done, and in what contexts, are different. We have already seen above the basic contexts and effects for musicking so next I will explore that more and then link these to the power of music coming from our social relationships. Following that we will have a better conception of music-in-context and how it 'works' so we can apply this to therapy and music therapies.

\section{Music and the excesses of language use}

The significance of language for the evolution of culture lies in this, that mankind set up in language a separate world beside the other world, a place it took to be so firmly set that, standing upon it, it could lift the rest of the world off its hinges and make itself master of it. To the extent that man has for long ages believed in the concepts and names of things as in aeternae veritates he has appropriated to himself that pride by which he raised himself above the animal: he really thought that in language he possessed knowledge of the world. The sculptor of language was not so modest as to believe that he was only giving things designations, he conceived rather that with words he was expressing supreme knowledge of things; language is, in fact, the first stage of occupation with science. (Nietzsche, 1995, p. 21)

Extending Nietzsche, we can now see that this world of language was built not upon the effects from the world, since saying the word 'cat' has no effect upon cats, only upon the effects on people. So, this alternative world of language, or the 'original Matrix' (Guerin, 2016a) or 'original virtual reality' (Guerin, 2016b), only ever worked because people in relationships with speakers do things and exchange because of the social reciprocities in everyday life. But Nietzsche is also correct that we now respond in life more to language than to the effects of the actual world-I can tell you many things about Tibet and its history but have never been there or even met a Tibetan.

Why do we seem to favor words over the real objects and events? Thinking back to the 'power' of words, this tells us that the effects coming from people are now more important or valuable in running our worlds than interacting with the objects themselves. All the multiple 'impressions' (possible language responses) we get walking into a new room are potential conversations with other people and can be useful when they are later raised as a topic by a current or future person ("Oh, I meant to tell you that I went into Don's house yesterday and he has these really lovely blue curtains and a cute dog."). This makes sense because almost everything we need in life now comes through other people, since we do not grow or make things ourselves directly anymore. Keeping relationships and reciprocities functioning, even with strangers like your boss, is the most valuable asset (or social capital) we have, so gathering or gleaning possible conversations is seriously important in life.

The first link to music, therefore, is that if musicking in all forms can provide similar social conversations or events with people, then it is likewise extremely important and will hold strong power. Going back earlier in this paper, this point covers a lot of the effects which were called cognitive, conversational, discursive or interpretive, and a few of the attentional effects. It also will involve all aspects or musicking including the organization and running of musical events (DeNora, 2013) since these 'conversations' which are provided or afforded by musicking go way beyond discussing the music itself. They can be about events, people, gossip, 'feelings', moods, technical aspects of music, comparisons, complaints, opinions, values, etc. (Guerin, 2003, 2016a). Being able to have these conversations is an effect, function, or outcome of engaging in any type of musicking, from listening 'passively' to being a professional musician.

As an example, Rowe and Guerin (2018) spent intensive time with metalheads talking (amongst other things, Rowe, 2018) about their beginnings with metal at school. In general, most had some form of bullying or ostracism happening but adopting the metal identity 'protected' them from this, 
since other kids left them alone. In multiple ways, which included lyrics of course, becoming metal afforded new social relationships and re-configured their old social relationships (which were negative in general). Like our kangaroos, this came through complex and varied aspects of 'being metal' and differed for different people (Rowe, 2018; Varas-Díaz \& Scott, 2016).

The second link from this to music follows from the point made earlier that our worlds are now heavily based around words rather than interacting with the effects from doing things to the world, and that this is due to the almost exclusive role now of social relationships in getting all our resources for living. Even though we mostly interact and exchange with strangers, our social relationships with them are vital because that is how we get everything we need. Instead of spending our time growing food and tending the cows, we spend a lot of our time maintaining multiple social identities with the many compartmentalized groups of strangers necessary to run our lives. Therefore, whatever can help negotiate our social interactions now is important. While language is the main activity for doing this, I am suggesting that music is a close second (along with religious and cultural activities which are not discussed here).

The point of these language problems, or the problems from the preponderance of language in our lives, is that music is often cited as a way of avoiding or replacing the constant language usage. That is, if we attend to music this can not only facilitate managing our social relationships, but it can also supplant, distract or reduce the constant language conversations engaging our worlds. As Carter put it in the quote given earlier: "... an evening of [musical] reminiscence or reverie after having checked his conscious, critical self at the door with his hat." Music can engage us (change attentional focus) away from language and discursive matters and this can be useful sometimes, especially with 'mental health' issues.

To give one example, which was from a prisoner in Texas and reported by Jackson (1972, cited in Paynter, 1992, p. 28): "When a man get to singing, he doesn't get time to think about the problems or the work... I can do a whole lot more work workin' by time than I can workin' loose... When I sing, picking cotton, before I know anything I can be three blocks ahead."

To give a personal example of this, like many other people I find Mahler's music very engaging and I find myself (afterwards) having stopped the constant language chit chat going on in my life, including that of the 'constant, critical self'. My explanation for this is that throughout Mahler's works there is almost always a strong leading 'voice' in the music, and in most of his music this is not a singer but an instrument leading as if it were a voice but with no words. This is not always a 'melody' or 'tune' but there is always one 'voice' in the foreground which engages my attention. With other music of dense harmonies without a leading voice, I find that language snippets of conversations reappear as 'thoughts' during my listening. The nature of these 'voices' in the music will be discussed in the next section, but I find that the way Mahler's music is written facilitates the shifting away from words and language-based thinking.

As another example more related to music therapies, many people like having background music playing when they are studying or concentrating in some other way while using language, whereas other people are just as adamant that they need silence. In the contextual approach here, the answer will depend upon how many concurrent conversational snippets arising from their world are 'active'. If their worlds or contexts are in conflict or there are many unresolved situations then there are likely to be many background conversations going on. Freud called these unconscious but placed them inside the head instead of the person's worlds (Guerin, 2017a).

Whether or not background music is useful for distraction will therefore depend on the full context and is not automatic. (1) If a person is in a context where multiple language thinking is happening frequently (perhaps they are in a conflict situation but trying to study), then music can reduce or supplant these but leave the main ('critical') language voice since that is what the studying requires (presuming it is language based study). (2) For someone with few background 'thoughts' or discourses, music is likely to weaken the very language voice they need for the studying and so music might not help their study. (3) For someone who always engages with 
music then having music in the background will also likely mean that the music will supplant the main language voice required (it is difficult to study and have Mahler in the background if you are a fan). (4) If the task is a non-language task in which background language thinking will interfere with the task then music can be useful, whereas silence might be a problem (like Jackson's example earlier).

The third link to music is more difficult to grasp but comes out of the question of how people respond when words fail: when they cannot explain what is going on, cannot say anything at all, or anything they might say has been punished. As Nietzsche wrote, we now act as if language can cover us socially for any problem that might arise in life, but there are many gaps in what language can do which we rarely recognize (Guerin, 2020a, Chapter 7): (1) if questioned repeatedly or criticized, our superficial 'explanations' fail us; (2) conversation and even language-thinking depend on other people but if most of our social relationships are in disarray then we might not be able to speak at all, since every alternative discourse we can muster will have been punished; and (3) there can also be events in life with so many contradictory consequences or ramifications that we cannot say anything at all and we describe these as terror, awe, sublime, or holy (Otto, 1966), depending upon the context (Bicknell, 2009). It is important for music therapies to note that such life situations will be common in contexts which engender the mental health behaviors (Guerin, 2017a).

In such situations of negative conflictual contexts or overpowering positive contexts, in which we cannot explain ourselves or talk in the normal way, there are still several ways we can respond with language and still perhaps get away with this socially. In discursive terms, we can employ strategies of hedging, bluffing, mentalisms, abstractions, replying with questions, personifications, the use of 'emotive' language, linguistic distractions, commonly acceptable 'explanations', and various stories and abstract theories (Guerin, 2019). These cover up the gaps in what we cannot say but the problem does not go away.

Of importance for this paper is that when we cannot explain or talk because of the above contexts, there are also typical non-discursive or non- -language responses people make. Some of these are just physical movements such as attempting to hurt or silence the people around you, but more common non-discursive responding includes: 'emotional' behaviors other than 'emotive language', poetry, crying, painting, music and other forms of art, and non-language use forms of distraction (Guerin, 2019).

In this sense, 'emotional' behaviors are just behaviors we commonly do when we cannot say or explain what is going on and some response is (socially) required (Guerin, 2020a). They are not 'expressing' or 'communicating' anything but they still have effects of course, and in this way musical and other non-language responses might be able to do things to change conflictual social relationships which language cannot. In a roundabout way, all these non-discursive responses might even help find alternative solutions by trying something musical or 'emotional', when words have failed, and so change the social relationships in other ways.

I once read that hysterical behavior is a reaching out for liberation by means of wild gestures. Unaware of the movements needed to secure their release, animals become hysterical and lose all control. And in their frenzy they often discover the right gesture to gain their freedman.

This reminds me of the liberating advantages of a primitive existence which is purely emotional. However hysterical, the primitive person draws upon so many contradictory feelings that the one capable of bringing about a sense of freedom finally comes to the surface, even if that person does not know it. (Clarice Lispector, 1984, p. 118)

What we call emotions therefore, in this approach, are responses we commonly do when (1) we cannot talk about what is happening and (2) it seems important to be able to respond in some way. Clarice Lispector's "primitive existence which is purely emotional" is really talking about a world in which language is not the main method of doing things to people.

This situation is common both during music and in mental health situations (Guerin, 2017a). In music, we cry, tremble or have chills in some music (Bicknell, 2009) when the musical tones 
affect us in a way that is important to utilize in our social relationships (in varied ways) but we cannot use language for this because the musical events fall through the gaps in language use. In mental health we are in bad situations which need the social relationships and other contexts to be changed but we cannot do this with words or even describe it in words (Guerin, 2017a, 2019). In such cases, we need music, poetry, dance. "Blues guitarists brought out all the extremes of the guitar. Turning their backs on tradition, they wanted the thing to sound bad, slightly out of tune, a mirror of their crying voice." (Daniels, 1981, p. 80). "But the person who says, 'I cried because the music was beautiful,' may have something else in mind. She may not be offering an explanation, so much as claiming that no explanation is possible." (Bicknell, 2009, p. 122).

\section{What does therapy do, anyway?}

I have now covered all too briefly what musicking looks like when contextualized, and especially the usually hidden role of social relationships and social exchanges in all this, rather than using mentalisms to place responsibility onto an agentive brain as popular writings do (Benzon, 2001). When I am listening to Mahler in 'raptures' this affords me multiple ways to work with my social relationships and exchanges, through conversational snippets and stories for example. My rapture arises because this is an important situation for my presentation and self-identity but what Mahler is doing to me, by blocking out my language thoughts with his strong voice style of music, means I am both aware (talking, thinking) that this is momentous but have no words I can use later for my audiences-hence the emotional 'rapture' or trance.

Before finally going on to apply this to music therapies, I will say something about psychotherapies and what they are doing to people. It must be remembered that because of the current bureaucratic system of psychotherapies, most therapy is conducted in an office bereft of musical instruments and is therefore conducted almost entirely through the use of language. Even when something arises not involving language, the client reports ver- bally to the therapist about this. So most current therapies are locked into using language exclusively.

In a review or 'deconstruction' of psychotherapies, Guerin (2017b) looked closely at 19 therapies (only language-based ones). Once the jargon, theories and 'explanations' were removed, all the therapies were doing similar things with their clients, and a comparison to social work showed the same. The therapies each said they had special and unique practices, but the differences were only in the jargon used. The main general thrusts of almost all the western therapies for goals and activities were to:

1. form a working relationship with a client in a stranger/ contractual relationship

2. solve smaller or more localized conflicts in the client's life which were amenable within an office 3. act as a new audience to train new behaviors and skills where appropriate

4. find out their talk and thinking around the problems and suffering they are having

5. attempt to act as a new audience to change those thoughts and talking in ways that should be beneficial and reduce the suffering, especially for broader life conflicts

As previously discussed, 4 and 5 were more frequent than 3 , showing how the language use problems were immensely important. Within dealing with language use problems, the following were the main 'techniques' used by most therapies, closely associated with cognitive behavior therapy but also used by social workers ironically:

1. Changing your thinking about something ("I am worthless")

2. Distracting your thoughts so something can be said to you without the internal criticizing and opposition'

3. Getting you to say out loud some of the things in your background responding to your life context which are not usually rehearsed or said out loud (and thereby get new outcomes from therapies)

The focus, then, is on avoiding the critical or dysfunctional language responses which are op- 
erative, or else trying to get clients to say some of their problems and so produce new ways for them to talk and think (new conversational strategies to change bad social situations). The problem with this alone is that many of the problem contexts cannot be talked, and cannot be changed by talking alo$n e$, since it is the social relationships and exchanges that need the change not the words. This is one way music therapy is useful.

What the analysis of contextualizing musicking allows us to see is that none of these therapeutic goals necessarily actually need to be done using words. Other ways of changing or adjusting social relationships can be just as effective. In terms of avoiding bad thoughts and trying to respond in ways that might produce new solutions to life context problems, music, art, poetry and dance can all provide other avenues since there is nothing special about language use except its extensively learned repertoire and the specificity of its effects. But even if it is specific, complex and well-learned, language use still depends upon changing social relationships and no amount of fancy words can guarantee that outcome.

An example of mixing language-based thoughtdistraction and other techniques of using 'social influence without words', is hypnosis (Erickson, Rossi \& Rossi, 1976). Several methods are used in hypnosis with the goal of distracting the 'critical mind' in exactly the way Elliott Cater wrote for music in the quote earlier. Some are more physical (attending to moving watches and the like), some are language-based distractions, and others are subtler (Erickson, Rossi \& Rossi, 1976). The goals are to distract the main 'voice' of the person (Mahler does this!), which will normally be critical in therapeutic situations, and then provide language-based suggestions for how to change the person's situation. Music does the first of these, as we have seen, but just listening and distraction by itself does not automatically change a person's social situation, although in many cases it might. Music therapy, therefore, could learn more from hypnosis and cognitive behavior therapies about doing the second part of this: how to direct the person to change once the critical voice is distracted.

\section{What does musical therapy do?}

There is a myth that 'mental illness' resides inside a person and to change things you need to do something to change them 'inside.' This is currently thought to be happening when you talk with someone and have them talk about their problems-you assume you are changing them 'inside'. More recent views are that 'mental illness' is made up of the behaviors we do in bad contexts, ones in which there are: contradictory pressures, blockages in what we are able to do especially in changing our social relationships, and conflicting social relationships which are necessary to maintain for resources (Guerin, 2017a, 2020b; Johnstone \& Boyle, 2018). In this way, talking is not changing the person 'inside' at all but changing their external social relationships by the shaping of the counsellors or therapists.

This means that there is not a 'tool box' of specialized techniques for helping people in such situations, rather, their worlds-social, cultural, political, patriarchal, economic, opportunities-need to be shaken up in some way but this is usually only attemtped through talking. It is not like medicine in which there are pathogens inside the body which need specific internal treatments. Most of the 'specialized tools' of cognitive behavior therapists are just variations on using language to change language (Guerin, 2017b).

What this means is that changing a person's worlds could be done in a number of other ways quite successfully once the goal becomes external change instead of a fictitious 'inside' change. This is where other therapies such as music therapy can be legitimately placed once language is seen as just one way-but a good way of course-for changing a person's life situation. And music therapy will be especially important in situations in which a person's social relationships are shaping difficulties for them to talk about what is happening, or getting language responses for what is happening. These eventually lead to crying and other non-discursive responses but we have seen that music is perfectly placed to allow new responding which might change messy social relationships. 
What can music therapy do?

Most of what I have reviewed on the effects of music is already being utilized well by music therapists, although many other uses of music are used in psychology and applied behavior analysis (Lim \& Draper, 2011; Madsen \& Prickett, 1987; Radocy \& Boyle, 1988).

But if we brush away the theories and abstractions which have gone with that, the links to a person's social relationships can be made more explicit and perhaps new solutions found. That is, instead of the goal from music being enjoyment or rapture, or trying to change the person 'inside', we can explicitly teach the person how to 'use' their musicking in their social lives to change their bad life situations. This is probably abundantly clear in larger group musicking (Clunies Ross \& Wild, 1984; DeNora, 2015; Moyle, 1986). But for work with individuals this can be made more explicit and actively shape and incorporate the effects of music into their conversations, stories, self-identity stories and narratives, etc. Music therapy joined to narrative therapies would be useful, for example ("Whereof one cannot speak, thereof one must make music or paint").

I am suggesting that much of this goes on in the major methods for change in music therapies already: song-writing, visualizations, improvisations, creativity, paying and listening to music geared towards change, discussing music and analysis, roleplaying, mediation with music, and singing. If we ignore the 'explanations' given currently for why these work, we can refocus our observations and techniques to more detailed contexts of music. As I have reviewed in this paper, music has emotional effects on the listeners; attentional effects or distractions; and discourses about music. However, each of these is primarily about effects from our social relationships which are powerful because it is our social exchanges which provide everything in our worlds.

In general, musicking is a broad set of events of learning to play music, performing music, organizing musical events, and listening to music. The effects of each of these can be very powerful and therefore can be utilized to change a person's life contexts, something people already report from their unsystematic uses of musicking. These effects do not rely on the musical sounds per se, which is why this paper has explored the broader external effects of music on a person's life. In these ways, music affects how a person can manage their social relationships, especially in providing discourses for this and in stopping negative language uses which have been shaped in their social relationships.

\section{What can we add to music therapy?}

In terms of more specific suggestions, several were given throughout the paper. Many of these are already used in music therapies, or used in some form. The main two changes are to consider more closely how bad social and discursive. environments or contexts of people can be changed through musicking of different types, and, where music is used for distracting painful or fictional language or thinking, consider more carefully how suggestions or contextual changes can be made rather than have the client do music and hope for the best that there will be external changes in their contexts.

\section{Use musicking to change people's environ-} ments. If just listening or performing music were in itself therapeutic, then many more people would be issue-free. Music therapies could advantageously follow hypnosis in this regard as to directly changing the client's contexts, offering verbal suggestions to change the client's contexts, or bringing in the relevant people from the client's world to engage with the client together in musicking.

\section{Use music as a response when no language uses} can be made. In therapeutic situations in which the clients and/or the therapist is at a loss for words, substitute music instead of resorting to fictitious words and explanations (Guerin, 2019). If a client is overwhelmed by a situation or event, ask them if they can play this to you, and perhaps like hypnosis ask them to play what it will be like when this feeling of being overwhelmed has passed. Many variations can be tried.

\section{Words do not have power in them so music is} just as important. Music therapists must remember that words and instructions do not have any power and, just like music, it is the negotiations and management of social relationships and exchanges of resources that is really driving language to be ef- 
fective. This means that in principle, music can be just as effective if we can arrange the social ecologies in a useful way.

4. Organizing musicking in itself will have many useful effects. It is not just composing, performing and listening that can be therapeutic but also organizing music events. This comes through clear in the work of DeNora (2015) and Ansdell (2014) and in the related therapeutic effects of dancing, ceremony, rituals, Koran reading events, walking and exercise, etc. But these are not substitutable, and you cannot just do one form with another group of people, since their effectiveness in changing social relationships depends upon how it is done as much as what is actually done. But all allow for groups of people to interact and re-shape their social relationships while musicking.

\section{Music relates to story-telling and self-identity.} Musicking, whether as a group or as an 'individual' (Guerin, 2001b) provides a way (or an excuse) for story-telling which is important in all parts of life, but especially in managing the self-identities we need to have our lives functioning well (Mattingly, 1994). It provides common ground for making friendships, it gives us something to talk about socially to build and manage social relationships. The stories can be about events, people, gossip, 'feelings', moods, technical aspects of music, comparisons, complaints, opinions, values, etc. Mixing music and narrative therapies would be useful when words are failing in a situation.

6. Musicking also changes our attention in observing the world and the responses we have. Music can block, distract and divert other sounds including language, from momentary stopping of thinking to trances. This is especially important for people in life situations in which there are no language responses they can make which will change the situations and the only language or non-language responses have become dysfunctional (crying, anger, isolation). Music in these ways helps us to avoid any anxiety and be calm, and this probably happens by music's effect of distracting us from negative thoughts and relationship conflicts.
7. Music can quieten the critical voice. Music can also distract us from the main directive and critical voices we might have or as a way of controlling many of the nagging language voices. Replacing these with musicking is therefore an important part of what music therapy can do and this could help with 'emotional' problems. Again, similar techniques are part of hypnosis and cognitive behavior therapy except that more direct instructions are shaped by the therapist as an audience, but this could be utilized in music therapy in the future.

\section{Music can replace a purely language-based} world. Having our worlds guided by and run through language leads to some poor outcomes for people (Guerin, 2017a). Music is one way to 'build' alterative responses to the world, to help us engage in the world, which do not involve language.

\section{Mental health is almost by definition difficult} to put into words. My definition of mental health is that the contextual origins are difficult to see (Guerin, 2017a), and if we knew where they arose from we would not even call it a mental health problem. This shows that non-language forms of therapy need to be on an equal footing with language-based therapies.

\section{Conclusions}

The main point music therapists can learn from all this, since they already do much of this but explain it more abstractly, is that these links can be made more explicit and shaped by the therapist once the 'internal' problems are 'turned inside out'. While engaging in music activities with clients, the stories and identities can be shaped also, the client can learn to observe when words are no longer providing functional responses to what is happening in their lives and use music instead, and when the client is in a bad 'emotional' state they can be taught to use music to 'think' through and change their life situations and especially their social relationships, rather than just plain listen to the music.

It is hoped that contextualizing music in this way, or at least in a new way, will provide new ideas to try, and which can be used to experiment with different 
clients in different ways. People spend a lot of time listening to music and while it might calm them or drive bad thoughts away for a time, music therapists need to be there to go beyond this and helps support all forms of musicking to reach out to the clients' social worlds and let changes happen to improve the clients' lives through all aspects of musicking. This contextual formulation allows us to see exactly how these external contexts in which clients are embedded arise from and can be changed through music.

\section{References}

Aiello, R. (1994). Music and language: Parallels and contrasts. In R. Aiello (Ed.), Musical perceptions (pp. 41-63). New York: Oxford University Press.

Ansdell, G. (2014). How music helps in music therapy and everyday life. London: Routledge.

Austerlitz, R. (1983). Meaning in music: Is music like language and if so, how? American Journal of Semiotics, 2, 1-12. https://doi.org/10.5840/ ajs 19832323

Barnes-Homes, Y., Barnes-Homes, D., Smeets, P. M., \& Luciano, C. (2004). The derived transfer of mood functions through equivalence relations: I. The Psychological Record, 54, 95-114.

Barthes, R. (1985). The responsibility of forms: Critical essays on music, art, and representation. London: Basil Blackwell.

Becker, J. (1979). Time and tune in Java. In A. L. Becker \& A. A. Yengoyan (Eds.), The imagination of reality (pp. 197-210). Norwood, NJ: Ablex.

Benzon, W. L. (2001). Beethoven's anvil: Music in mind and culture. London: Oxford University Press.

Bicknell, J. (2009). Why music moves us. NY: Palgrave. https://doi.org/10.1057/9780230233836

Blacking, J. (1995). Music, culture, \& experience: Selected papers of John Blacking. Chicago: University of Chicago Press.

Cahill, J., Barnes-Homes, Y., Barnes-Homes, D., Rodriguez-Valverdes, M., Luciano, C., \& Smeets, P. M. (2007). The derived transfer of mood functions through equivalence relations: II. The Psychological Record, 57, 373-389.

Carter, E. (1977). The writings of Elliott Carter:
An American composer looks at modern music. Bloomington: Indiana University Press.

Chanan, M. (1995). Repeated takes: A short history of recording and its effects on music. NY: Verso.

Clunies Ross, R., \& Wild, S. A. (1984). Formal performance: The relations of music, text and dance in Arnhem Land clan songs. Ethnomusicology, 28, 209-235. https://doi.org/10.2307/850758

Daniels, R. (1981). Blues guitar: Inside \& out. Port Chester, NY: Cherry Lane Music.

DeNora, T. (2011). Music-in-action: Selected essays in sonic ecology. Burlington, VT: Ashgate.

DeNora, T. (2015). Music asylums: Wellbeing through music in everyday life. London: Routledge.

Duffin, R. W. (2007). How equal temperament ruined harmony (and why you should care). NY: Norton.

Erickson, M. H., Rossi, E. L., \& Rossi, S. I. (1976). Hypnotic realities: The induction of clinical hypnosis and forms of indirect suggestion. New York: Irvington.

Feld, S. (1984). Sound structure as social structure. Ethnomusicology, 28, 383-409. https://doi. org/10.2307/851232

Feld, S., \& Fox, A. A. (1994). Music and language. Annual Review of Anthropology, 23, 25-53. https://doi.org/10.1146/annurev. an.23.100194.000325

Gabreilsson, A., \& Lindström Wik, S. (2003). Strong experiences related to music: A descriptive system. Musicae Scientiae, 7, 157-217. https://doi. org/10.1177/102986490300700201

Gibson, J. J. (1979). The ecological approach to visual perception. Boston: Houghton Mifflin.

Guerin, B. (1990). Gibson, Skinner, and perceptual responses. Behavior and Philosophy, 18, 43-54.

Guerin, B. (2001a). Replacing catharsis and uncertainty reduction theories with descriptions of the historical and social context. Review of General Psychology, 5, 44-61. https://doi. org/10.1037/1089-2680.5.1.44

Guerin, B. (2001b). Individuals as social relationships: 18 ways that acting alone can be thought of as social behavior. Review of General Psychology, 5, 406-428. https://doi org/10.1037/1089-2680.5.4.406

Guerin, B. (2003). Language use as social strategy: A review and an analytic framework for the 
social sciences. Review of General Psychology, 7, 251-298. https://doi.org/10.1037/10892680.7.3.251

Guerin, B. (2016a). How to rethink human behavior: A practical guide to social contextual analysis. London: Routledge. https://doi. org/10.4324/9781315648903

Guerin, B. (2016b). How to rethink psychology: New metaphors for understanding people and their behavior. London: Routledge.

Guerin, B. (2017a). How to rethink mental illness: The human contexts behind the labels. London: Routledge. https://doi. org/10.4324/9781315462615

Guerin, B. (2017b). Deconstructing psychological therapies as activities in context: What are the goals and what do therapists actually do? Revista Perspectivas em Análise do Comportamento, 8, 97-119. https://doi.org/10.18761/pac.2016.040

Guerin, B. (2019). What do therapists and clients talk about when they cannot explain behaviours? How Carl Jung avoided analysing a client's environments by inventing theories. Revista Perspectivas em Anályse Comportamento, 10, 76-97.

Guerin, B. (2020a). Turning psychology into social contextual analysis. London: Routledge.

Guerin, B. (2020b). Turning therapy into social action. London: Routledge.

Guerin, B., Leugi, G. B., \& Thain, A. (2018). Attempting to overcome problems shared by both qualitative and quantitative methodologies: Two hybrid procedures to encourage diverse research. The Australian Community Psychologist, 29, 74-90.

Johnstone, L. \& Boyle, M. with Cromby, J., Dillon, J., Harper, D., Kinderman, P., Longden, E., Pilgrim, D. \& Read, J. (2018). The Power Threat Meaning Framework: Towards the identification of patterns in emotional distress, unusual experiences and troubled or troubling behavior, as an alternative to functional psychiatric diagnosis. Leicester: British Psychological Society.

Kaemmer, J. E. (1989). Social power and music change among the Shona. Ethnomusicology, 33, 31-45. https://doi.org/10.2307/852168

Kassler, J. C. (Ed.). (1991). Metaphor: A musical dimension. Sydney: Currency Press.
Kingsbury, H. (1988). Music, talent, and performance: A conservatory cultural system. Philadelphia: Temple University Press.

Lamont, A. (2012). Emotion, engagement and meaning in strong experiences of music performance. Psychology of Music, 40, 574-594. https://doi.org/10.1177/0305735612448510

Landis-Shack, N., Heinz, A. J. \& Bonn-Miller, M. O. (2017). Music therapy for posttraumatic stress in adults: A theoretical review. Psychomusicology, 27, 334-342. https://doi. org/10.1037/pmu0000192

Lim, H. A., \& Draper, E. (2011). The effects of music therapy incorporated with applied behaviour analysis verbal behaviour approach for children with autism spectrum disorders. Journal of Music Therapy, 48, 532-550.

Lispector, C. (1984). Selected chônicas. NY: New Directions.

Madsen, C. K., \& Prickett, C. A. (Eds.). (1987). Applications of research in music behaviour. London: University of Alabama Press.

Mattingly, C. (1994). The concept of therapeutic 'emplotment'. Social Science \& Medicine, 38, 811-822. https://doi.org/10.1016/02779536(94)90153-8

Merriam, A. P. (1964). The anthropology of music. Evanston, IL: Northwestern University Press.

Moyle, R. M. (1986). Alyawarra music: Songs and society in a central Australian community. Canberra: Australian Institute of Aboriginal Studies.

Nattiez, J-J. (1990). Music and discourse: Towards a semiology of music. Princeton, NJ: Princeton University Press.

Nietzsche, F. (1995). Human, all too human, 1. Stanford, CA: Stanford University Press.

Nyman, M. (2006). Towards (a definition of) experimental music. In C. Cox and D. Warner (Eds.), Audio culture: Readings in modern music (pp. 209-220). NY: Continuum.

Otto, R. (1966). The idea of the holy: An inquiry into the non-rational factor in the idea of the divine and its relation to the rational. London: Oxford University Press.

Paynter, J. (1992). Music and people: The import of structure and form. In J. Paynter, T. Howell, R. Orton \& P. Seymour (Eds.), Companion to con- 
temporary musical thought (Vol. 1, pp. 25-33). New York: Routledge.

Radocy, R. E., \& Boyle, J. D. (1988). Psychological foundations of music behaviour. Springfield, IL: Charles C. Thomas.

Rosen, C. (1988). Sonata forms. New York: W. W. Norton \& Company.

Rouget, G. (12985). Music and trance: A theory of the relations between music and possession. Chicago: University of Chicago Press.

Rowe, P. (2018). Heavy metal youth identities: Researching the musical empowerment of youth transitions and psychosocial wellbeing. London: Emerald Publishing. https://doi. org/10.1108/9781787568495

Rowe, P., \& Guerin, B. (2018). Contextualizing the mental health of metal youth: A community for social protection, identity and musical empowerment. Journal of Community Psychology, 46, 1-13. https://doi.org/10.1002/jcop.21949

Seeger, A. (1987). Why Suyá sing: A musical anthropology of an Amazonian people. Cambridge: Cambridge University Press.

Seeger, C. (1962). The music process as a function in a context of functions. Inter-American Insitute for Musical Research Yearbook, 2, 1-36.

Shepherd, J. (1992). Music as cultural text. In J. Paynter, T. Howell, R. Orton \& P. Seymour (Eds.), Companion to contemporary musical thought (Vol. 1, pp. 128-155). New York: Routledge.

Small, C. (1998). Musicking: The meanings of performing and listening. Hanover: University Press of New England.

Varas-Díaz, N., \& Scott, N. (Eds.). (2016)._Heavy metal music and the communal experience. NY: Lexington Books.

Vink, A. \& Hanser, S. (2018). Music-based therapeutic interventions for people with dementia: A mini-review. Medicines, 5, 109-115. https:// doi.org/10.3390/medicines5040109

Weinstein, D. (2000). Heavymetal: The music and its culture. New York: Da Capo Press.

Winegarner, B. (2013). The Columbine effect: How five teen pastimes got caught in the crossfire and why teens are taking them back. New York: Lulu.

\section{Informações do Artigo}

Histórico do artigo:

Submetido em: 03/12/2018

Primeira decisão editorial: 06/12/2019

Aceito em: 14/012/2019 